\title{
Tectonics of the Symbol
}

\author{
Dr. Livio Dimitriu, Professor of Architecture and Theory/History \\ Sponsored by Pratt Institute School of Architecture \\ 200 Willoughby Avenue, Brooklyn, NY, USA, 11205 \\ usainst@gmail.com
}

\begin{abstract}
There are two reoccurring representations of the Cross in Christian icononography. If they are approached tectonically instead of a symbolism disconnected from fabrication, the attention focuses on the crucified body acting as a structurally stabilizing element. This allows for a totally new approach to the meaning of the Crucifixion and its symbolism, this time literally rising from the reality of fabrication.

The two representations of the cross are fused with their respective meanings. The standard cross is simply symbolic, where the T-cross is symbolic but also tectonic. The result forms a "stable" image at many levels of discourse. The body of Christ nailed to the Cross provides the triangulation required for a stable structure. It is not the Cross but the body of the Savior that provides stability and thus salvation.

The Colonel Uricariu Monument built by the architect Livio Dimitriu in the Ghencea Military Heroes Cemetery in Bucharest, Romania (1998), exemplifies the plastic potential of this new palimpsest-like logic as related to the representation of the cross over time. The development of the project argues for a process of design which does not follow the standard obsession with the linear development of the image and frozen early canon, but allows materials, methods, environmental factors, societal concerns and a multitude of other real factors, to take the design into constantly surprising directions until reaching the moment of building.
\end{abstract}

\section{Essay}

This project for Colonel Uricariu Monument was developed and concluded in a rapid succession of sketches all the way through its detailed execution drawings during a five-hour period. A mere thought and cultural references were used only as a catalyst for the design process. The transformation of the thought was due to a series of factors all involving reality checks in addition to formal concerns. The process was governed by an understanding and respect for the spirit of the early Christian faith as embodied in its thought and in the Orthodox faith. Above all, there was a constant reference to the simplicity of execution, particularly given the local material and technology available in Romania, and other assorted pragmatic concerns.

At every step of the design process the proposal changed under self-imposed and welcomed pressures and limitations offered by working with marble. The development of the final form appears and is non-linear. The only linearity present in the process is that of a concern with ease of fabrication given the limited machinery and craft available in Romania, the physical characteristics of the local Ruschita marble and its reaction to weathering in a climate that features rather drastic seasonal changes of temperature, resistance to vandalism, and cost control.

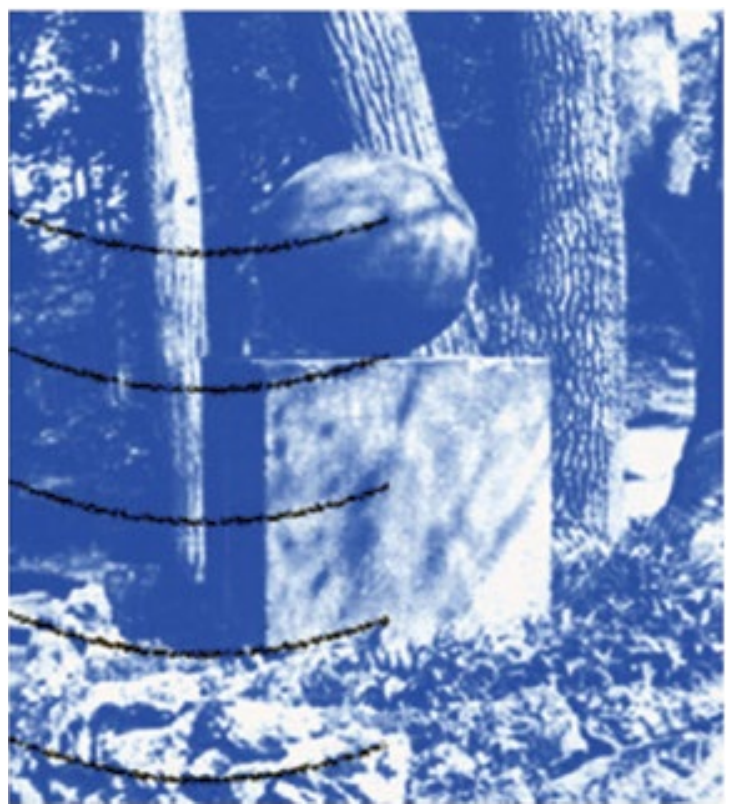

Figure 1. Johann Wolfgang von Goethe, The Altar of Good Fortune / Monument for Charlotte, Weimar, Germany (1777) 
The point of departure was marked by a relatively little-known monument designed by Goethe, The Altar of Good Fortune (1777). This Illuminist homage to his lover Charlotte, placed in the poet's garden in Weimar, Germany (Figure 1). This beginning established the criteria for abstraction that remained present throughout the process and continued to dominate the final result. The motif of the cross was introduced immediately after, along with the lyrical theme of a perceptual illusion involving the image of a heart. Human perception and scale followed almost instantly.

Spherical volumes were abandoned rather early due to cost and material waste, and uncertainties regarding the craft and capability of the local stone cutters ability to turn out such a shape flawlessly. Solutions that involved protruding elements and/or assembly of standard thickness pre-cut slabs were soon eliminated because of concerns with the local seasonal variations of temperature as well as vandalism. (Figure 9)

The monument's measurements were determined by the height of the warrior, 1.80 meters, standing up-right in death as in life. The verticality is not only a metaphor. It refers to the tradition of many cultures around the world to have heroes buried vertically. The plan proportions ultimately became an anthropomorphic 30x50 cm due to limitations of weight and handling that could be accommodated by the type of lift-forks available locally and onsite. This limitation forced a welcomed frontality for the monument, with a perceptual rotation in space and around the monument achieved through the motif of the cross and its typological variations wrapping around this stella, and with the dynamic "axonometric heart" placed at one of its lower corners.

The outer surfaces of the marble block are slightly bush-hammered while the recessed surfaces of the carved-out cross motif are polished. This surface treatment virtually minimizes the blinding effect under sun-light that marble can have if seen as a large polished marble volume. In this monument, light is only reflected off the minimal surfaces receding in the mass of the block, and place in evidence the name of the deceased and dates. These factual concerns resonate deeply however with the early Christian Church. For St. Augustin, it is the Christian soul that shines bright, regardless of the outer body and worldly shape.
Galla Pacidia in Ravenna, like so many other early Christian religious buildings, echoes this view (Figure 2).

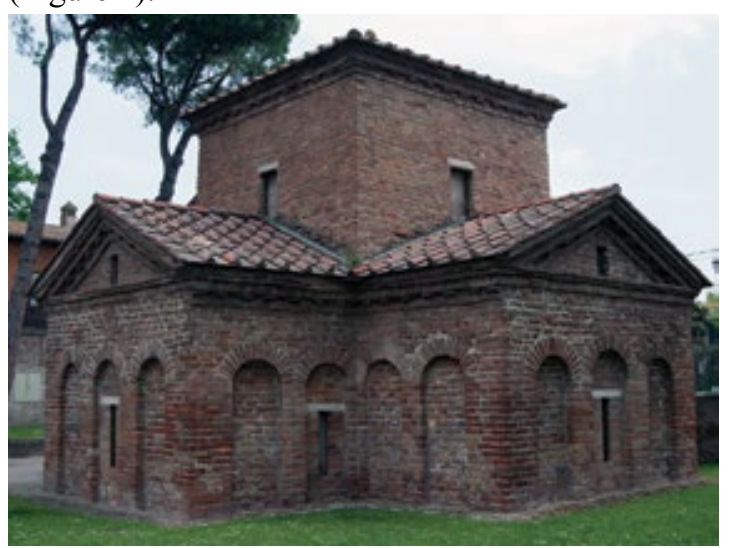

Figure 2. Galla Placidia Church, Ravenna, Italy, (425$450 \mathrm{AD})$.

Galla Placidia's simple, exposed and weathered brickwork façade highly contracts with the rich soul of gold and polychrome mosaics on the inside. The monument incorporates the spirit of a tradition and religion. In the case of the Monument for Colonel Uricariu, the architecture and its contemporary language also alludes biographically to an imperfect body, bush-hammered by the war, in contrast with the human spirit that continued to shine bright in life as in afterlife.

The front of the monument carries the machinecut incision of the standard four arms cross. The arms of the cross literally wrap around and embrace the body of marble and become, on the opposite face, the "true" three arms cross of martyrdom. The western painting tradition abounds in examples of both, and yet precious little has been analytically written on the subject. (Figure 3).

The four armed cross is a symbol. The three arms cross is the actual instrument of torture, as revealed by any effort at understanding efficient and simply detailed wood construction. It is the martyred body on the three arms cross that renders the structure stable by triangulation of the static forces at play. It is the crucified body, and thus the meaning of the sacrifice of the Saviour, that makes the symbol statically strong. (Figure 4). This is the tectonics of the symbol.

The wrapping of the two crosses joined in a continuous figure around the body of the monument is an invitation for the viewer to move around in space, despite the relative frontality of the work 


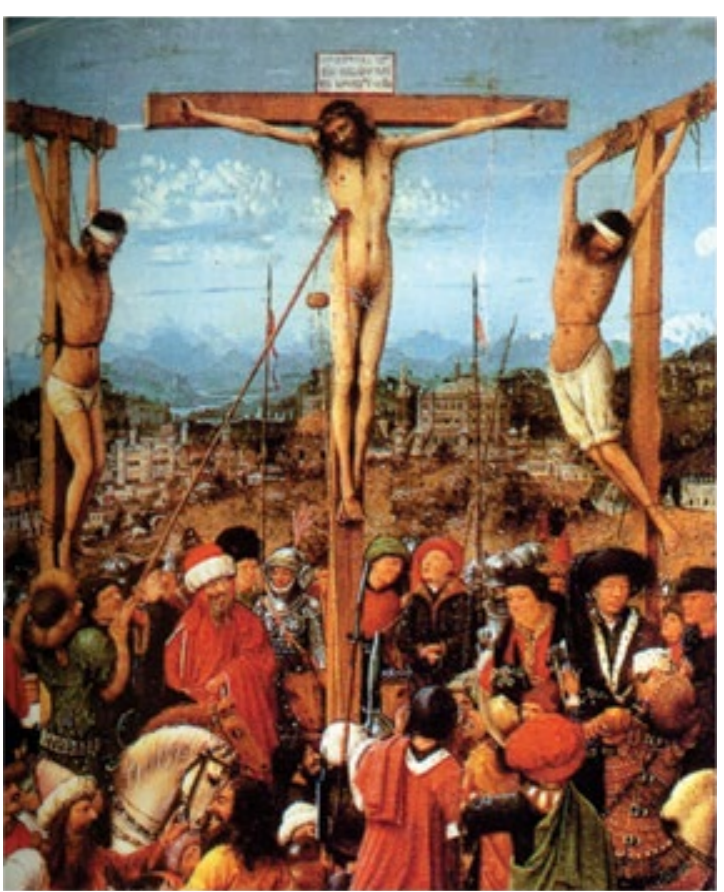

Figure 3. Hubert and/or Jan van Eyk. Detail, The Crucifixion, c. 1420-1425. Tempera and oil on canvass transferred from panel, The Metropolitan Museum of Art, New York, USA.

in a procession similar to the women in Christ's entourage that had witnessed the Crucifixion. Two matching semi-circular small incisions on two adjacent faces of the marble volume, and one of the lower corners, generate in anamorphic perspective the reading of a heart, modest and timid, but a reminder of an ever-present gratitude as well as an allusion to Christ's heart bleeding for us all. The "heart" is readable from eye level as one looks down while leaning against the monument. The carved inscription and the "heart" were gilded at a later date, so as to further underline the captive warm meaning frozen inside the coldness of the marble. (Figure 5, 6)

Doina Uricariu matched this essay in stone with a volume of poetry entitled The Axonometric Heart. The volume honours the memory of Colonel Uricariu, consistent with the family's centuries-long writing tradition traced back to Axinte Uricariul, the medieval chronicler of Romania.

While our position initially involves the preconceived abstraction contained in Goethe's monument only as a point of departure, it becomes eventually free of the dictatorship of this image.

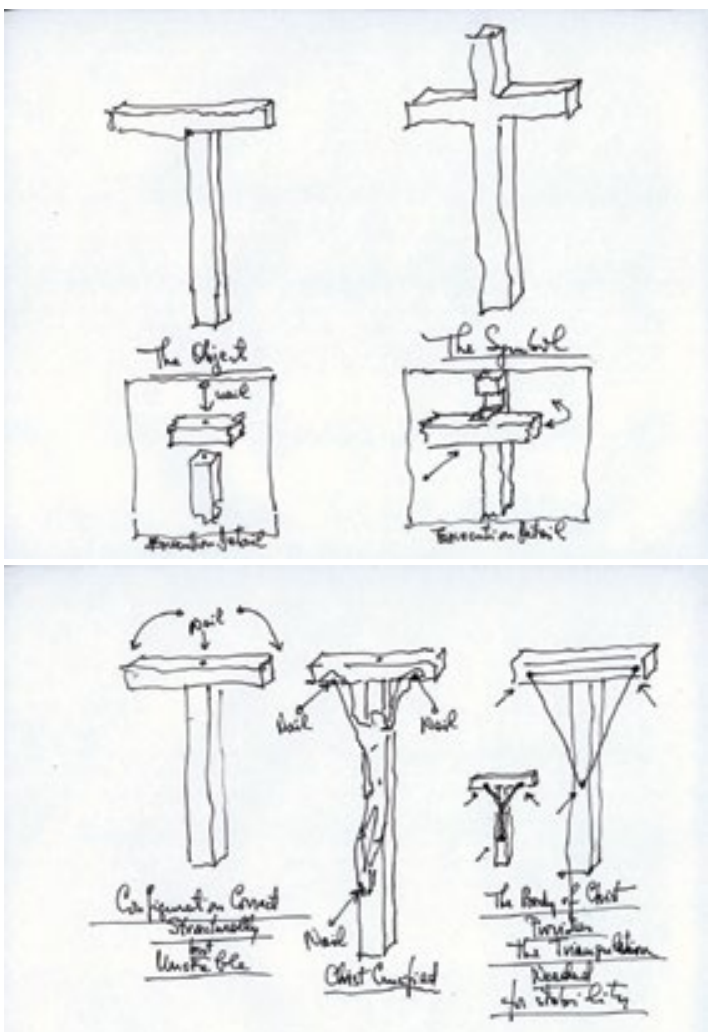

Figure 4. Livio Dimitriu, sketches. The tectonics of the Cross: actual feasible fabrication and the crucified and nailed body stabilizing an unstable structure.

The monument owes its abstraction to a rich and layered meaning involving the numerologically significant number 11, the total number of standard machine-generated cuts performed onto the marble block. The rotation of the stone block on the cutting bed during execution makes one recall the torture of the Saviour while the nails were driven into His body while He was still on the ground. (Figure 7, 8 ). The anamorphic heart is a carefully inserted rhetorical device generated by two additional halfround cuts that were obtained by simply lowering a circular blade of a selected diameter into the marble, and only half way its diameter.

Similarly to the volume and space of Galla Placidia, the spirit of this project attempts to address and to incorporate the continuity over millennia of a quote from Pindar, appropriated by St. Augustin in his Confessions, and brought into modernity by Paul Valéry in his poem The Maritime Cemetery: "The light foot-steps of a white 

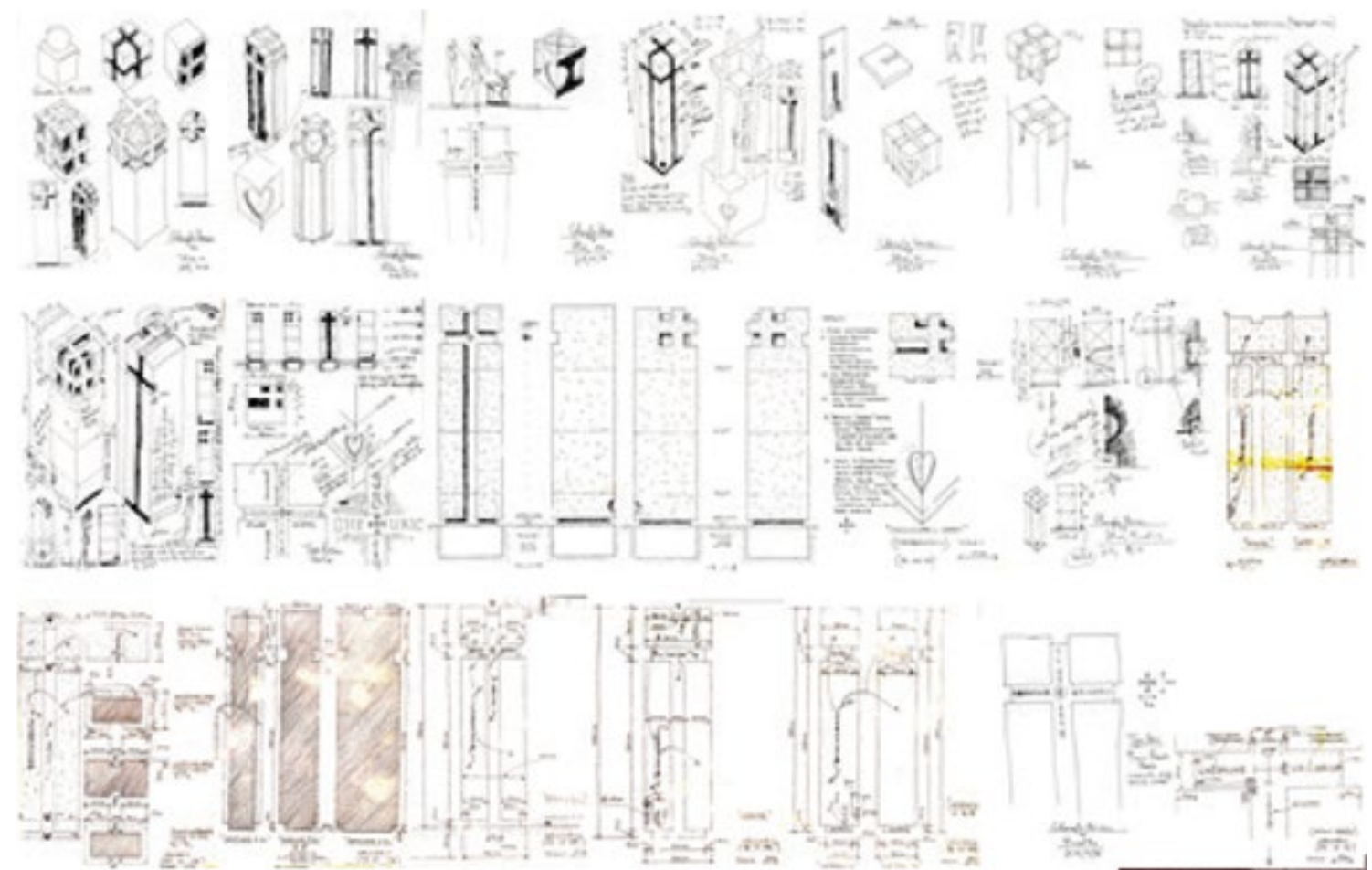

Figure 9. Livio Dimitriu, arch. Non-linear design development, first sketch to finished project.

dove on the roof of my soul". The project's conception constantly hovers between the perception as dictated by the physical eye and that of the axonometric governing the eye of the mind.

\section{Bibliography:}

Livio Dimitriu, Monument for Colonel Gheorghe Uricariu, in Arhitext Magazine, No. 5, May 2004, Bucharest, Romania.
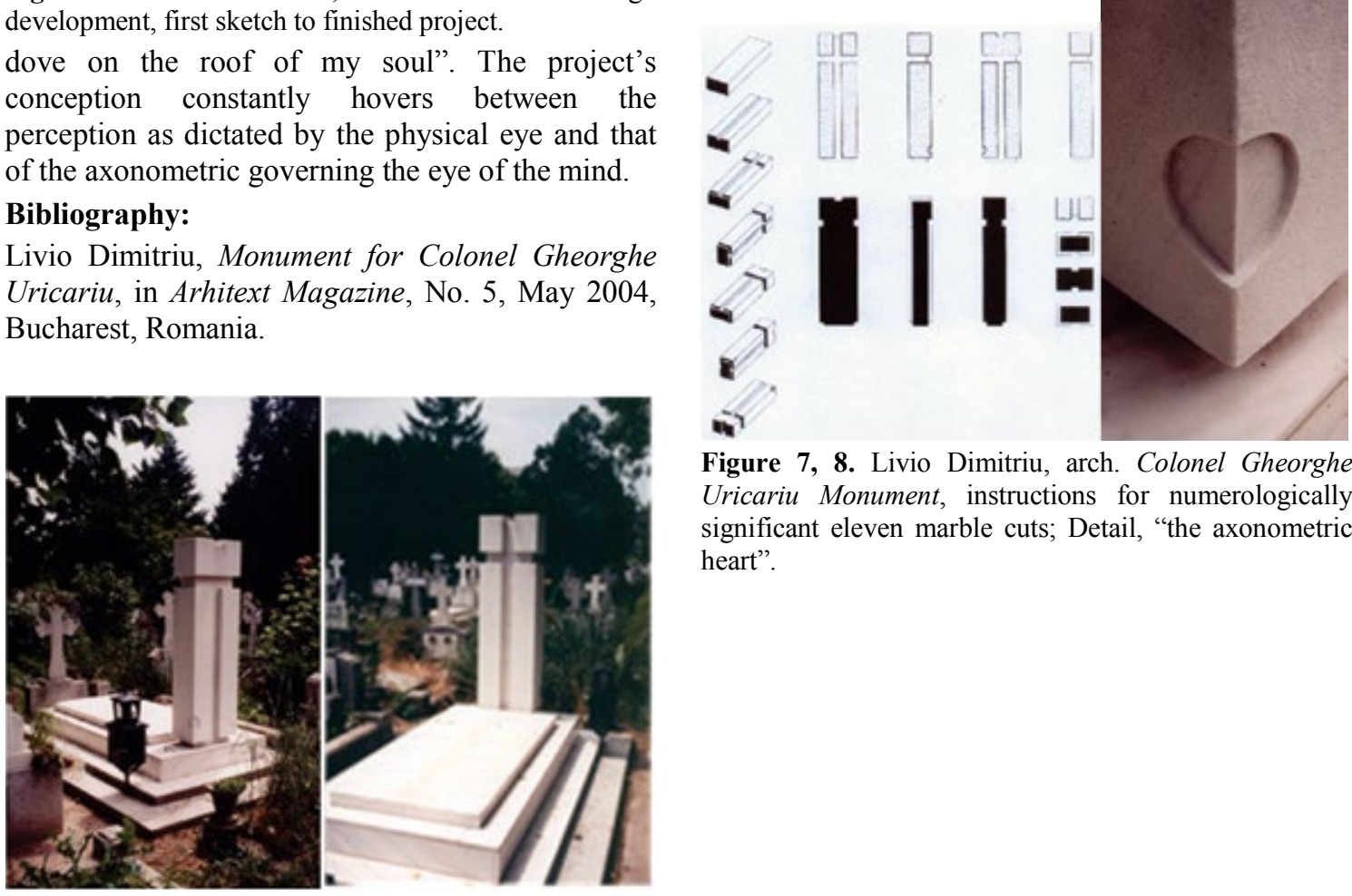

Figure 7, 8. Livio Dimitriu, arch. Colonel Gheorghe Uricariu Monument, instructions for numerologically significant eleven marble cuts; Detail, "the axonometric heart".

Figure 5,6,. Livio Dimitriu, arch. Colonel Gheorghe Uricariu Monument, 1998. Rear view with corner 


\section{Biographical Sketch:}

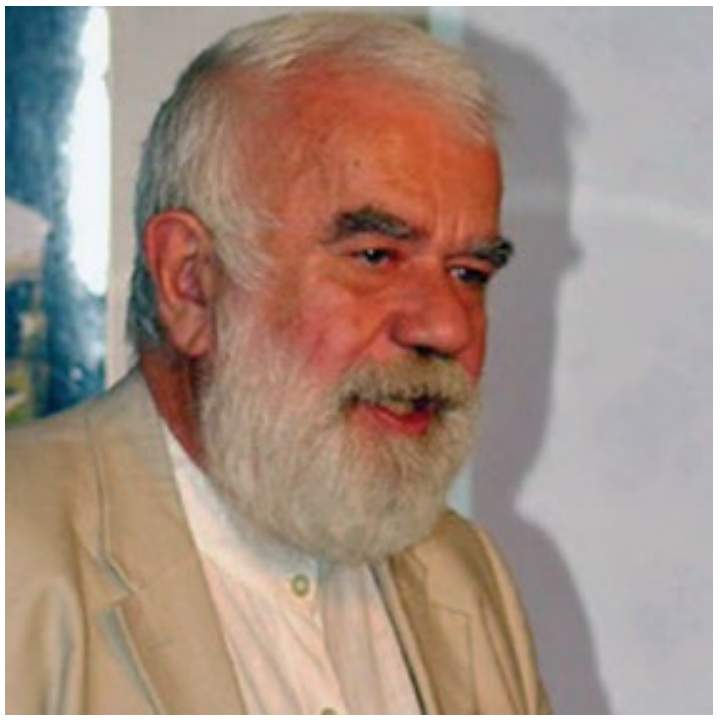

Dr. Livio Dimitriu is a Serbian-born American educator and architect in private practice in New York since 1978. His urban design and architecture projects received fifteen national and international awards in the Nord America, Europe, and Asia. His projects have been exhibited major museums and dozens of galleries and other institutions in twenty eight countries. Dr. Dimitriu has authored and/or contributed to thirty four volumes in ten countries and on three continents, along with articles and projects published in over one hundred magazines and periodical worldwide.

Dr. Dimitriu accepted a Ph.D. with the Highest Honors in Theory/History of Architecture from the "Ion Mincu" University for Architecture and Urbanism in Bucharest/Romania, where he was also awarded an Honorary Distinguished Professor Bene Merenti. He received an Honorary Master Architect in Stone from Antica Corporazione in Verona/Italy, and a B.Arch from the Cooper Union in New York. He is currently a tenured full professor at Pratt Institute in New York. Over 200 of his students received national and international awards in architecture and urban design over the past 37 years, including a US National First Prize for digital design in Form $Z$.

He founded and co-founded respectively two series of avant-garde publications in New York: New York Architects and Pamphlet Architecture. He is a founding member of the Islandic School of Architecture, an Olivetti Foundation Scientific Committee member, and a Senior International Editor with a cumulative 25 years of service with Controspozio, Octogon, and Arhitext magazines in Italy and Romania. Dr. Dimitriu was a Senior Fulbright Scholar to Europe, received a research grant from the National Endowment for the Arts/USA, and repeated research grants from the Romanian Government and Pratt Institute/USA.

Dr. Livio Dimitriu founded USA Institute in 1978, a public service design and research organization active in Nord America, Europe, and Asia, and is chief editor of USA Books He held academic appointments/directorships at twenty one universities/higher education institutions in Nord America, Europe, and Asia. 